Atos de Pesquisa em Educação - ISSN 1809-0354

Blumenau, v. 12, n.3, p.661-676, set./dez. 2017

DOI: http://dx.doi.org/10.7867/1809-0354.2017v12n3p661-676

\title{
“DE REPENTE, NÃO MAIS QUE DE REPENTE”: O PROCESSO DE INSERÇÃO PROFISSIONAL DOCENTE NO ATENDIMENTO EDUCACIONAL ESPECIALIZADO
}

\section{“SUDDENLY, NO MORE THAN SUDDENLY": TEACHERS'S ENTRANCE PROCESS IN SPECIALIZED EDUCATIONAL SERVICE}

\author{
RENGEL, Juliana Testoni dos Santos \\ julianatsrengel@gmail.com \\ UNIVILLE - Universidade da Região de Joinville
}

CORDEIRO, Aliciene F. Machado alicienermachado@hotmail.com UNIVILLE - Universidade da Região de Joinville

\begin{abstract}
RESUMO O Atendimento Educacional Especializado (AEE) é uma relevante proposição na atual política nacional de Educação Especial. Investigando-o no âmbito de uma rede municipal de ensino no norte catarinense, identificou-se um baixo interesse dos docentes em atuar nesse serviço. Diante disso, o presente artigo propôs-se a conhecer o processo de inserção profissional docente no AEE da referida rede de ensino. Conduziram-se entrevistas semiestruturadas com cinco docentes, sendo suas respostas interpretadas à luz de pressupostos da Análise de Conteúdo. Evidenciou-se que a seleção de docentes é realizada principalmente por indicação de equipes diretivas escolares, que parecem basear suas recomendações em traços de personalidade, o que pode ter relação direta com a evasão e a baixa disponibilidade dos docentes da rede para atuar no AEE.
\end{abstract}

Palavras-chave: Atendimento Educacional Especializado. Educação Especial. Formação Docente. Trabalho Docente.

ABSTRACT The Specialized Educational Service (SES) is a relevant proposal in the current national policy of Special Education. Investigating it in the scope of public schools located in Santa Catarina state's north region, it was identified that teachers have a low interest to work in this service. Therefore, this paper aimed to know teachers's entrance process in SES of these municipal public schools. Semistructured interviews were conducted with five teachers, and their answers were interpreted by the light of Content Analysis assumptions (FRANCO, 2012). It was evidenced that the selection of teachers is carried out mainly by indication of school management teams, which seem to base their recommendations on personality traits, which may be directly related to the evasion and the low availability of the teachers to work in SES.

Keywords: Specialized Educational Service. Special Education. Teacher's Formation. Teacher's Work.

\section{INTRODUÇÃO}


Atos de Pesquisa em Educação - ISSN 1809-0354

Blumenau, v. 12, n.3, p.661-676, set./dez. 2017

DOI: http://dx.doi.org/10.7867/1809-0354.2017v12n3p661-676

O Atendimento Educacional Especializado (AEE) se trata de um serviço cuja finalidade é complementar ou suplementar o processo de escolarização por meio da disponibilização de serviços, recursos de acessibilidade e estratégias de ensino e aprendizagem que possam diminuir ou mesmo eliminar as barreiras para seu desenvolvimento e participação social, como disposto no art. $2^{\circ}$ da Resolução CNE/CEB no 4/2009 (BRASIL, 2009). Majoritariamente, é realizado em Salas de Recursos Multifuncionais (SRM) da própria escola ou em outra escola de ensino regular, no turno inverso deste.

O AEE configura-se como "[...] uma das proposições de maior relevância na atual política de inclusão relacionada à Educação Especial" (MICHELS; CARNEIRO; GARCIA, 2012, p. 26) e possui como público-alvo exposto na resolução supracitada, alunos com deficiência, seja esta de natureza física, intelectual, mental ou sensorial. Além destes, também engloba os alunos com transtornos globais do desenvolvimento, que apresentam um quadro de alterações no desenvolvimento neuropsicomotor, comprometimento nas relações sociais, na comunicação ou estereotipias motoras. São também atendidos alunos com altas habilidades ou superdotação, entendidos como "[...] aqueles que apresentam um potencial elevado e grande envolvimento com as áreas do conhecimento humano, isoladas ou combinadas: intelectual, liderança, psicomotora, artes e criatividade" (BRASIL, 2009, p. 1). Neste estudo, optou-se por chamar este alunado de estudantes público-alvo da Educação Especial.

Em concordância com Michels, Carneiro e Garcia (2012), compreende-se que investigar os desdobramentos de políticas e/ou diretrizes relacionadas à Educação Especial nas redes de ensino permite apreender como, no plano local, elas têm se concretizado. Evidencia-se, nesse sentido, que por meio deste estudo é possível contribuir com a compreensão da situação local, isto é, como o município pesquisado tem se organizado frente às diretrizes nacionais para a Educação Especial, no que diz respeito à inserção de professores no AEE. Como salientou Mazzotta (2010, p. 81), "[...] é essencial que a realidade de nossas escolas, especialmente as públicas, seja conhecida".

Acredita-se, também, que a presente pesquisa pode contribuir com avanços no entendimento que, de forma geral, se tem sobre esse serviço e o trabalho dos 


\section{Atos de Pesquisa em Educação - ISSN 1809-0354 \\ Blumenau, v. 12, n.3, p.661-676, set./dez. 2017 \\ DOI: http://dx.doi.org/10.7867/1809-0354.2017v12n3p661-676}

professores que nele atuam, bem como colaborar para o processo de escolarização dos estudantes considerados público-alvo da Educação Especial, dado que, como destacou Bernardes (2014, p. 55):

[...] há necessidade de publicação de estudos na temática [trabalho docente no AEE] para auxiliar nas discussões sobre como esse serviço tem se configurado no cotidiano das escolas e se, de fato, está contribuindo com o processo de escolarização dos estudantes.

A pesquisa aqui apresentada buscou aprofundar as discussões anunciadas em investigação conduzida por Bernardes (2014) acerca do trabalho docente no AEE pelas vozes de professoras especializadas ${ }^{1}$ no contexto específico de uma rede municipal de ensino no norte catarinense. Um dos aspectos evidenciados em seu trabalho foi um baixo interesse, por parte das docentes desta rede, em trabalhar nesta modalidade de educação escolar.

De acordo com informações obtidas junto ao Núcleo de Educação Especial da Secretaria Municipal de Educação do município pesquisado, o reduzido número de docentes interessadas em atuar no AEE deve-se à "[...] não identificação/perfil dos(as) professores(as) em trabalhar com pessoas com deficiência e também à falta de compreensão em relação ao trabalho realizado pelo professor(a) especializado(a)" (BERNARDES, 2014, p. 63). A autora ressaltou, ainda, que:

[...] quando há interesse, os(as) professores(as) são chamados no Núcleo de EE [Educação Especial] para conversar sobre a vaga e conhecer o trabalho do AEE. É nesse ponto que o(a) professor(a), até então interessado(a), desinteressa-se, ou mesmo por não atingir os critérios estabelecidos para atuar no AEE, como trabalhar 40 horas no município e ter formação em pedagogia, em que nesses casos, o(a) professor(a) não pode assumir a função. (BERNARDES, 2014, p. 63)

Além deste reduzido número de docentes interessados, houve considerável evasão de professoras que ingressaram nesta modalidade de educação escolar desde 2010, ano em que se iniciou o processo de implementação das SRM nas escolas municipais, até 2013 , ano em que foi realizada a pesquisa. Conforme dados da Secretaria Municipal de Educação obtidos por meio de entrevista:

\footnotetext{
1 "Professoras especializadas" foi o termo escolhido pela autora para referir-se às professoras do Atendimento Educacional Especializado, atuantes em Salas de Recursos Multifuncionais.
} 


\section{Atos de Pesquisa em Educação - ISSN 1809-0354 \\ Blumenau, v. 12, n.3, p.661-676, set./dez. 2017 \\ DOI: http://dx.doi.org/10.7867/1809-0354.2017v12n3p661-676}

[...] de 2009 a 2013, houve a desistência de nove professoras do AEE. Além disso, no momento estão precisando de oito professores(as) para as novas SRM que precisam ser abertas. Mas, mesmo enviando convite para os diretores escolares e via internet para professores, há um baixo interesse. (BERNARDES, 2014, p. 63, nota de rodapé)

Corroborando os dados até então apresentados, Silva (2014) constatou, ao estudar sobre a formação de professores do AEE no estado de Goiás, que os critérios para o ingresso como professora especializada em SRMs não obedece aos dispositivos legais e que nem a formação, nem a legislação, são os principais critérios usados na seleção e ingresso para atuar no AEE.

[...] observamos que as professoras demonstram um desconforto em aceitar o convite ou a convocação para assumirem o AEE nas SRMs, tendo em vista que algumas são iniciantes na carreira docente, outras se sentem despreparadas para tal função e há, ainda, um segundo grupo de professoras que estão prestes a se aposentarem. [...] Discutindo a forma de ingresso no AEE foi mencionada a readaptação profissional, que acontece quando o professor regente é acometido de um problema de saúde que dificulta sua atuação no ensino regular, então ele é deslocado para outro espaço dentro da escola. (SILVA, 2014, p. 131-132)

As constatações da autora evidenciam que a entrada no AEE está mais relacionada a uma aceitação - de um convite, convocação ou realocação - do que efetivamente a uma escolha intencional e específica do professor. Apesar de não estudar o AEE em si, Gatti (1996) observou que, para um terço das professoras dos anos iniciais e finais da rede pública dos estados de São Paulo, Minas Gerais e Maranhão, pesquisadas em atividade no início dos anos 1990, a docência foi uma profissão que "aconteceu" chamando a atenção para o fato de que, em muitos casos, fatores circunstanciais marcaram ou até mesmo motivaram suas escolhas pelo magistério.

Salienta-se, ainda, que "essas condições de ingresso e permanência como professoras certamente estão associadas às perspectivas perante seus alunos e seus modos de agir com eles, seus objetivos e metodologias de trabalho" (GATTI, 1996, p. 87). Considera-se, neste sentido, que existe uma oportunidade - mais que isso, uma necessidade - de analisar os impactos das condições de ingresso no AEE nas perspectivas, modos de agir, objetivos e metodologias de trabalho dos professores que, em última instância, afetam o processo de escolarização dos 


\section{Atos de Pesquisa em Educação - ISSN 1809-0354 \\ Blumenau, v. 12, n.3, p.661-676, set./dez. 2017 \\ DOI: http://dx.doi.org/10.7867/1809-0354.2017v12n3p661-676}

alunos com deficiência, transtornos globais do desenvolvimento e altas habilidades/superdotação, que aqui serão chamados como estudantes público-alvo da Educação Especial.

No Rio Grande do Sul, ao investigar as configurações do AEE na perspectiva da rede municipal de ensino de Gravataí, Delevati (2012) identificou que a forma de ingresso dos professores no AEE não acontece por meio de concurso público específico para esta função. A maioria dos entrevistados é concursada, mas para outras áreas, como anos iniciais, anos finais e orientação/supervisão escolar. Com relação à experiência profissional anterior, grande parte deles já havia vivenciado ou ainda vivenciava a docência em instituições ou escolas especializadas, cujas práticas e concepções são por vezes embasadas por uma vertente médicopedagógica e/ou pelo ensino substitutivo².

Já na região centro sul do Paraná, um dos docentes participantes da pesquisa conduzida por Carnevale et al. (2013) relatou que sua entrada no AEE como docente ocorreu por meio de concurso público voltado especificamente para esta modalidade, diferentemente das docentes pesquisados por Bernardes (2014), Silva (2014) e Delevati (2012).

Os achados das autoras supracitadas possibilitam questionar as formas de ingresso e os critérios utilizados pelas escolas e secretarias municipais e estaduais de educação ao selecionar professores para atuação no AEE. A experiência profissional anterior em Educação Especial parece ser um dos critérios considerados no processo de contratação, ainda que não seja um requisito para a docência no AEE, de acordo com as diretrizes brasileiras ${ }^{3}$.

A partir desses dados, é possível compor um entendimento de que a entrada no AEE nem sempre sugere intencionalidade prévia por parte do professor no

\footnotetext{
${ }^{2}$ A vertente médico-pedagógica, segundo Januzzi (2004), implica em uma forma de ação pedagógica junto aos estudantes público-alvo da Educação Especial que se orienta mais por questões médicas e biológicas e nas quais subjaz uma concepção de deficiência como doença. Já o ensino substitutivo consiste numa modalidade educacional realizada em instituições especializadas que, apesar de direcionada especificamente a estudantes público-alvo da educação especial, não possibilita a sua interação com outros estudantes sem deficiência (como pode acontecer no ensino comum) e neste sentido podem contribuir para sua segregação social.

${ }^{3}$ Os requisitos para atuação como professor no Atendimento Educacional Especializado resume-se ao exposto na Resolução n 4/2009, art. 12: "Para atuação no AEE, o professor deve ter formação inicial que o habilite para o exercício da docência e formação específica para a educação especial" (BRASIL, 2009, p. 3).
} 


\section{Atos de Pesquisa em Educação - ISSN 1809-0354 \\ Blumenau, v. 12, n.3, p.661-676, set./dez. 2017 \\ DOI: http://dx.doi.org/10.7867/1809-0354.2017v12n3p661-676}

processo de escolha profissional pela Educação Especial. Assim, delineou-se como objetivo deste estudo conhecer o processo de inserção profissional docente no AEE de uma rede municipal de ensino no norte catarinense, prosseguindo, para tal, um caminho investigativo cujos aspectos metodológicos serão relatados a seguir.

\section{ASPECTOS METODOLÓGICOS}

Esta pesquisa foi pautada em uma abordagem qualitativa, que valoriza os sentidos e significados atribuídos pelos sujeitos àquilo que vivenciam e procura compreender em que condições e circunstâncias essas vivências foram engendradas, sem necessariamente excluir aspectos quantitativos. Assim como exprimiram Gatti e André (2011, p. 29):

[...] assume-se, nesta perspectiva, que destes sentidos e significados é que se alimenta nosso conhecer e são eles que traduzem as mudanças dinâmicas no campo social, no campo educacional, cuja compreensão pode trazer uma aproximação do real mais condizente com as formas humanas de representar, pensar, agir, situar-se.

Com base nesta perspectiva, foi por meio dos sentidos e significados atribuídos por cinco professoras atuantes no AEE de uma rede municipal de ensino no norte catarinense que se buscou conhecer o processo de inserção de professores nesta modalidade de ensino na referida rede. Para isso, utilizou-se como instrumento para coleta de dados uma entrevista semiestruturada, cujo roteiro de perguntas continha apenas uma questão: "Como você se tornou professora do AEE?".

Atendendo à Resolução № 466/2012 do Conselho Nacional de Saúde, a coleta de dados teve início somente após a emissão do parecer de aprovação $n^{\circ}$ 830.595, de 31/10/2014, do projeto de pesquisa do qual este estudo faz parte, pelo Comitê de Ética em Pesquisa com Seres Humanos da universidade.

No que tange aos critérios de inclusão para seleção de participantes para a pesquisa, elencaram-se os seguintes: ser docente na rede municipal de ensino pesquisada, localizada no norte catarinense; atuar no AEE desde os primeiros anos em que as SRM foram implantadas, em 2010 e 2011. Solicitaram-se à Secretaria Municipal de Educação no município pesquisado nomes de docentes que 
Atos de Pesquisa em Educação - ISSN 1809-0354

Blumenau, v. 12, n.3, p.661-676, set./dez. 2017

DOI: http://dx.doi.org/10.7867/1809-0354.2017v12n3p661-676

atendessem a tais critérios e, dos oito nomes recebidos, cinco docentes os atenderam, de fato.

As cinco professoras foram convidadas a participar voluntariamente da pesquisa, tendo recebido e assinado um termo de consentimento livre e esclarecido que Ihes garantia a preservação de sua identificação nominal. Em virtude disso, conferiram-se às cinco docentes codinomes inspirados em escritoras da língua portuguesa: Adélia, Cecília, Florbela, Helena e Sophia.

Com relação à caracterização das participantes, optou-se por realizar uma descrição genérica do grupo de professoras, também no intuito de preservar a identificação das mesmas. Assim sendo, no tocante à faixa etária, a maioria das docentes possui entre 30 e 40 anos de idade, sendo seus anos de nascimento situados nas décadas de 1970 e 1980. Quanto à formação acadêmica, todas possuem graduação em Pedagogia ou Curso Normal Superior. Todas também realizaram pós-graduação (especialização) com formação específica em AEE. Com relação ao tempo de docência, todas atuam como professoras há 10 anos ou mais, trabalhando no AEE há pelo menos 4 anos.

Por estarem na docência há 10 ou mais anos, pode-se afirmar que nenhuma das professoras entrevistadas encontra-se no início da carreira docente, mas suas histórias no AEE são relativamente recentes. No entanto, ainda que compartilhem algumas características em comum, a forma como cada uma ingressou no AEE nem sempre coincidiu, e é sobre este aspecto que se debruçarão as análises no próximo item. Este processo de análise dos dados fundamentou-se em alguns pressupostos da Análise de Conteúdo (FRANCO, 2012), que procura desvelar, por meio de uma análise sistemática, sentidos e significados expressos de forma explícita ou implícita no conteúdo das mensagens que são emitidas por alguém, sejam estas verbais (orais ou escritas), gestuais, silenciosas, figurativas ou documentais.

No caso deste estudo, partiu-se das mensagens verbais orais emitidas pelas participantes para conhecer o processo de inserção profissional docente no AEE da rede municipal de ensino estudada. A análise do conteúdo das mensagens baseouse em critérios como recorrência, contradição e complementaridade que, segundo Franco (2012), são indicadores dos quais se podem lançar mão no momento de interpretar os dados, que serão apresentados e discutidos no tópico a seguir. 


\section{Atos de Pesquisa em Educação - ISSN 1809-0354 \\ Blumenau, v. 12, n.3, p.661-676, set./dez. 2017 \\ DOI: http://dx.doi.org/10.7867/1809-0354.2017v12n3p661-676}

\section{RESULTADOS E DISCUSSÃO}

Propondo-se a conhecer o processo de inserção profissional docente no AEE de uma rede municipal de ensino no norte catarinense, foi possível identificar que, ainda que em alguns casos houvesse interesse prévio em atuar no referido serviço, para a maioria das professoras, essa inserção profissional aconteceu como no trecho do Soneto de Separação, de Vinícius de Moraes: "de repente, não mais que de repente" 4 .

Para duas professoras entrevistadas nesta pesquisa, a possibilidade de trabalhar no AEE veio ao encontro de um interesse prévio em atuar na Educação Especial, como expressaram Florbela e Helena:

"Uma das minhas professoras da faculdade já sabia desse meu interesse pela Educação Especial e por coincidência na primeira escola onde eu fui trabalhar ela era Auxiliar de Direção. Quando começaram a contratar as pessoas para - AEE, eles [Secretaria da Educação] perguntavam nas escolas: 'Qual professora que você tem que tem esse perfil? Que gosta, que queira trabalhar com AEE?' Aí ela já lembrou do meu nome, perguntou se eu queria, e lógico que eu queria, gosto muito do meu trabalho aqui, me realizo com o trabalho no AEE." (Florbela).

"Eu falei para a minha diretora: 'Se precisarem indicar nome, eu quero que a senhora indique meu nome, porque eu quero trabalhar aqui nessa sala [de recursos]'. Tinha uma professora que [...] já conhecia o meu trabalho, e [...] era coordenadora do CEAPE e eles [Secretaria da Educação] pediram para ela indicar nomes de professoras, para oferecerem essas salas multifuncionais e a especialização em AEE. Ela indicou o meu nome [...] e de mais duas professoras. Nós fomos chamadas na Secretaria da Educação e elas explicaram para nós que teríamos direito de fazer essa especialização em AEE pelo MEC e que futuramente iríamos trabalhar nessa sala multifuncional a qualquer momento, e as outras duas professoras dessa escola não quiseram. E eu quis. Eu falei: 'Eu quero... E quero trabalhar lá na minha escola!"” (Helena).

\footnotetext{
${ }^{4}$ A título de informação, o Soneto de Separação de Vinícius de Moraes é composto por quatro estrofes, sendo a expressão "de repente, não mais que de repente" utilizada pelo autor nas últimas duas, a saber: "De repente, não mais que de repente / Fez-se de triste o que se fez amante / E de sozinho o que se fez contente / Fez-se do amigo próximo o distante / Fez-se da vida uma aventura errante / De repente, não mais que de repente" (MORAES, 2006, p. 15).
} 


\section{Atos de Pesquisa em Educação - ISSN 1809-0354 \\ Blumenau, v. 12, n.3, p.661-676, set./dez. 2017 \\ DOI: http://dx.doi.org/10.7867/1809-0354.2017v12n3p661-676}

No entanto, esta não é a realidade da maioria das professoras ingressantes no AEE desta rede de ensino. A forma repentina que parece caracterizar o movimento de inserção profissional da maioria das docentes nesta modalidade de ensino foi evidenciada pelas narrativas de duas professoras entrevistadas, que utilizaram a expressão "cair" para descrever como foram suas aproximações da Educação Especial, e especificamente do AEE:

"Anteriormente eu tinha vontade de ser aeromoça [...]. Por que eu caí no AEE? Eu digo: 'Por que é que eu fui cair no AEE...”' (Adélia).

"Na Educação Especial foi o que eu te disse mesmo, eu caí de paraquedas" (Sophia).

A expressão por elas cunhada convida à reflexão sobre como elas se tornaram professoras desta modalidade de educação escolar. Buscando uma referência em dicionários, é possível compreender que a expressão "cair”, em um contexto como o utilizado pelas entrevistadas, remete a significados como "ser domado por, ficar submetido, sucumbir" (AULETE, 2012, p. 140). Já uma expressão como "cair de paraquedas", utilizada por Sophia, pode significar admirar-se diante de algo imprevisto ou inesperado (MICHAELIS, 2009).

De fato, a maioria das participantes da pesquisa foi surpreendida ao receber o convite para atuar no AEE, pois não haviam manifestado interesse previamente. $O$ relato de Sophia remete a uma ruptura não somente no âmbito de sua profissão, mas de sua vida, a partir do ingresso no AEE:

"Minha vida foi antes e depois de AEE. Eu jamais imaginei que fosse para a Educação Especial, jamais. Quando eu fazia faculdade, nós tínhamos uma colega que já era da Educação Especial e eu a chamava de louca. Eu dizia: 'Não, imagina! Trabalhar com criança especial, com criança com deficiência? Jamais! Só para quem for louco...' E olha onde é que eu estou" (Sophia).

Em alguns casos, foi possível constatar que o convite para atuar no AEE foi feito quando as professoras ainda estavam em estágio probatório na rede municipal de ensino, o que para elas dificultava uma recusa, como explicitou Cecília: 
Atos de Pesquisa em Educação - ISSN 1809-0354

Blumenau, v. 12, n.3, p.661-676, set./dez. 2017

DOI: http://dx.doi.org/10.7867/1809-0354.2017v12n3p661-676

"Eu passei no concurso público e fui para a rede municipal de ensino. [...] Chegando na escola, tem aquela apresentação toda. Me apresentei e já me disseram: 'Ah, você vai pegar a turma do Fulano. Tem um Síndrome de Down lá que ninguém dá conta. Você vai para aquela turma". Nova, né? Tem que ir" (Cecília).

Também se identificou que, no processo de seleção de docentes para o ensino especializado, a equipe diretiva das escolas e a coordenação dos Centros de Apoio Pedagógico (CEAPE) são consultadas pela Secretaria Municipal de Educação para indicação de professores que tenham perfil para trabalhar com estudantes público-alvo da Educação Especial. Florbela, uma das entrevistadas, explicou que:

"Quando eles [Secretaria Municipal de Educação] começaram a contratar as pessoas para o AEE, perguntavam nas escolas [para a equipe diretiva]: 'Qual professora que você tem que tem esse perfil? Que gosta, que queira trabalhar com AEE?'” (Florbela).

Ao relatar sua vivência, Cecília ilustrou como este processo ocorre na prática:

"O diretor falou assim: 'Sabe que você tem perfil para trabalhar com surdo?' Eu falei: 'O senhor está louco! Nunca trabalhei!'. [O diretor disse:] "Não, mas você tem um jeito para trabalhar com surdo e você vai trabalhar na sala de recursos com surdo'. Eu falei: 'O senhor está louco? Meu Deus, eu não sei nada!'. [O diretor disse:] 'Não, você vai e você vai aprender'. E abriu a porta e me jogou, sabe? E eu fui" (Cecília).

No relato de Cecília, percebe-se a existência de uma angústia, tanto dela, como professora diante do desconhecido, quanto de seu diretor, em relação à necessidade de implementar e manter o AEE na escola. Nota-se, também, um jogo de força e poder que atravessa essa relação e remete, como exprimiu Tragtenberg (1985), a um tipo de organização escolar que legitima as relações sociais de poder e produz, por meio da hierarquia administrativa e pedagógica, uma dinâmica de controle, vigilância e punição. Essa dinâmica, ainda que seja vivenciada pelos diferentes atores que participam do processo de escolarização, nem sempre é percebida por eles, pois por já estar instituída pode ser tomada como algo natural, que sempre existiu. 


\title{
Atos de Pesquisa em Educação - ISSN 1809-0354 \\ Blumenau, v. 12, n.3, p.661-676, set./dez. 2017 \\ DOI: http://dx.doi.org/10.7867/1809-0354.2017v12n3p661-676
}

Quando Cecília narrou que o diretor da escola havia the atribuído um perfil para trabalhar junto a estudantes com surdez, questionou-se à entrevistada que perfil era este, em sua concepção:

\begin{abstract}
"Quando ele [diretor] conversou comigo, perguntei para ele: 'Mas por que o senhor acha que [tenho perfil]?' [O diretor respondeu:] 'Primeira coisa: você tem muita vontade de aprender. E outra coisa: o carinho, atenção que você dá para essas crianças é diferente'. E ainda disse: 'Juntando o carinho, a atenção, a vontade de aprender, o carinho e a atenção, só vai para frente". E eu acho que foi isso mesmo que impulsionou, sabe? Porque eu via [as crianças] com outro olhar. Não é que 'a criança com deficiência ela precisa ser sempre olhada diferente porque ela é diferente', não, é um olhar diferente. Um olhar de carinho, de atenção, um olhar de ver qual a necessidade dela, o que ela necessita nesse momento. Ela necessita que eu sente ali, que eu pare, que eu olhe, que eu dê atenção para ela, depois ela vai? É esse o olhar que eu acho que... Sabe? Que eles perceberam... Porque eles diziam assim: 'Meu Deus, Cecília! Você sai da sala dos professores, as crianças com deficiência, os surdos na verdade, que tinham bastante, vem tudo em cima de você'. Eu falei: 'Pois é'. Porque eu sou uma pessoa que consegue contato com eles, consigo conversar com eles, consigo, consigo... Então... Aí vai criando aquele vínculo. Eu acho que foi isso." (Cecília).
\end{abstract}

Ao ser questionada se o modo como o diretor a descreveu era também o modo como se percebia, Cecília respondeu enfaticamente que sim. A reflexão direciona-se, neste ponto, ao fato de que "ser carinhosa, atenciosa e ter vontade de aprender" são atribuições associadas - tanto pela professora quanto pelo diretor - a um perfil para se trabalhar com alunos público-alvo da Educação Especial. Diante desta constatação, algumas questões podem ser levantadas: Existe um perfil para se trabalhar com estes estudantes? Se sim, que perfil é este? No que está baseado?

No exemplo de Cecília, nota-se que este perfil é pautado em determinados traços de personalidade ou características pessoais. Consolidando as falas das cinco professoras, verificaram-se dez características utilizadas para descrever uma espécie de perfil para se trabalhar com tais alunos: "Ser atenciosa, carinhosa, paciente, acreditar na capacidade e potencial dos alunos, desenvolver um olhar diferente, que busca identificar a necessidade do aluno no dado momento, que não deixa o aluno 'jogado' na sala de aula, que consegue estabelecer contato/vínculo com ele, que busca adaptações na forma de ensinar e que tem vontade de aprender". 


\section{Atos de Pesquisa em Educação - ISSN 1809-0354 \\ Blumenau, v. 12, n.3, p.661-676, set./dez. 2017 \\ DOI: http://dx.doi.org/10.7867/1809-0354.2017v12n3p661-676}

Lima (2010), ao realizar um estudo bibliográfico acerca dos enunciados contidos em fontes nacionais e internacionais sobre docentes considerados como referências no processo de escolarização de estudantes público-alvo da Educação Especial, identificou os seguintes aspectos:

[...] professores com conhecimentos e habilidades; professores que se aproximem das experiências que são dos outros; e da sua própria aprendizagem, sua própria experiência (experiências que devem ser constantemente refletidas); professores com versatilidade e grande autonomia (competências criativas e complexas) por meio de uma prática continuada, reflexiva e coletiva; professores dispostos a exporem-se diante de si mesmos, aceitando seus próprios limites e fragilidades; professores não propensos a aderir receituários preconceituosos e autoritários; professores com uma clara integração entre teoria e prática; professores com atitudes de trabalhar em equipe, de cooperação com os outros atores e de intervenção no processo educativo e pela aceitação da diferença; professores-pesquisadores que buscam trabalhar em equipe, trocando saberes e experiências [...]; professores-pensadores, reflexivos e confiantes em experimentarem novas práticas; professores conscientes de processos sociais em que estão inseridos, como meio de facilitação do desenvolvimento profissional e da aprendizagem. (LIMA, 2010, p. 96-97).

Este "perfil para trabalhar com estudantes considerados público-alvo da Educação Especial" que parece circular nas escolas e foi evidenciada nas dez características relatadas pelas docentes traz consigo implicações que merecem ser problematizadas para evidenciar seus riscos. A começar pela própria ideia de perfil, que ao atribuir todas essas características ao professor, pode responsabilizá-lo individualmente pelo processo de aprendizagem do estudante, quando é o trabalho colaborativo entre os envolvidos neste processo que se destaca "como condição necessária para a existência de práticas educativas inclusivas" (RENGEL; CORDEIRO; STEINER, 2015, p. 1366).

Reforçar nos discursos e práticas que um perfil como este, que valoriza a dimensão afetiva e relacional da prática docente, mas silencia outras dimensões igualmente importantes, como saberes e técnicas pedagógicas, é esperado de um professor que irá atuar no AEE, pode contribuir para a perpetuação do que Michels, Carneiro e Garcia (2012) chamam de espontaneísmo nas ações docentes, em que a deficiência do estudante e a relação professor-aluno ganham centralidade em detrimento da preocupação em trabalhar conhecimentos específicos e organizar um planejamento que contemple os conteúdos escolares. 
Atos de Pesquisa em Educação - ISSN 1809-0354

Blumenau, v. 12, n.3, p.661-676, set./dez. 2017

DOI: http://dx.doi.org/10.7867/1809-0354.2017v12n3p661-676

Além disso, foi possível observar que é tênue a linha que diferencia "sugerir" a um professor que considere o AEE como possibilidade de atuação profissional e "compelir" um docente em estágio probatório a iniciar o trabalho neste atendimento "porque tem perfil" e "vai receber todo apoio". Percebe-se novamente um jogo de forças que tensiona as relações entre os envolvidos no processo de escolarização de estudantes público-alvo da Educação Especial: a equipe diretiva, de um lado, é pressionada para "fazer o AEE funcionar", e para isso precisa de professores. De outro, há os docentes da rede que parecem se sentir persuadidos a atuar nesta modalidade de ensino. Considerando que a maioria não tem interesse em nela atuar, seja por não identificação, por não ter formação específica ou conhecimento a respeito de como funciona o trabalho docente neste espaço, que podem fazer a Secretaria Municipal de Educação, as equipes diretivas das escolas e demais participantes da gestão escolar pública? Indicar docentes parece ter sido o caminho encontrado pela rede. No entanto, ressalta-se que a prática de indicação tem sido, por vezes, transmutada em uma prática de indução, que coloca os professores em uma difícil posição e pode gerar, posteriormente, evasão dos docentes.

Outra questão a ser problematizada a partir da pressuposição de que existe um perfil para se trabalhar com estudantes público-alvo da Educação Especial, que pode ser descrito pelas dez características anteriormente citadas ${ }^{5}$, é o lugar em que se coloca, no discurso, o estudante com deficiência - que passa a ser aquele que, primeiramente, precisa de afeto (e por isso, de uma professora atenciosa, carinhosa e paciente). Seu processo de aprendizagem de conteúdos escolares, neste caso, permanece em segundo plano e, consequentemente, a atividade de ensinar algo a alguém, própria do professor, também.

Ao afirmar que uma professora "tem perfil" para trabalhar no AEE por "ser atenciosa e carinhosa", imprime-se nela uma identidade docente, que por sua vez imprime uma identidade ao seu alunado - "aquele que precisa de atenção e carinho". Essas identidades, no entanto, são forjadas não somente nem

\footnotetext{
${ }^{5}$ 1. Ser atencioso; 2. Carinhoso(a); 3. Paciente; 4. Acreditar na capacidade e potencial dos alunos; 5. Desenvolver um olhar diferente; 6 . Buscar identificar a necessidade do aluno no dado momento; 7 . Não deixar o aluno 'jogado' na sala de aula; 8. Conseguir estabelecer contato/vínculo com o aluno; 9. Buscar adaptações na forma de ensinar; 10 . Ter vontade de aprender.
} 


\section{Atos de Pesquisa em Educação - ISSN 1809-0354 \\ Blumenau, v. 12, n.3, p.661-676, set./dez. 2017 \\ DOI: http://dx.doi.org/10.7867/1809-0354.2017v12n3p661-676}

restritamente na relação professor-aluno, mas na relação com vários determinantes que fazem parte do meio cultural. Januzzi (2004, p. 10) explicou que:

[...] o modo de se conceber, de se pensar, de se agir com o diferente depende da organização social como um todo, na sua base material, [...] em íntima relação com as descobertas das diversas ciências, das crenças, das ideologias, apreendidas pela complexidade da individualidade humana na sua constituição física e psíquica. Daí as diversas formas de o diferente ser percebido pela sociedade nos diversos tempos e lugares.

Ao salientar o carinho e a atenção na ação pedagógica, revela-se a persistência de uma concepção desprofissionalizante da docência, em que esta é definida como atividade missionária ou vocacionada que dispensa a necessidade de formação específica, condições de trabalho, carga horária adequada e remuneração digna (ALVES, 2006). Ressalta-se, novamente, que nesta concepção tira-se o foco do que confere à docência o status de profissão e lhe diferencia das demais atividades profissionais: a especificidade dos saberes necessários para e da atividade de fazer alguém aprender algo. Como exprimiu Tardif (2013), o professor trabalha um objeto (conhecimentos produzidos/acumulados historicamente pela humanidade), com sujeitos (estudantes, principalmente) e em função de um projeto (instruir, educar, transformar).

\section{CONSIDERAÇÕES FINAIS}

Diante das problematizações levantadas, pôde-se inferir que em alguns casos o ingresso docente no AEE em uma rede municipal de ensino no norte catarinense tem sido realizado em condições precárias; o professor aceita o convite, convocação ou realocação sem necessariamente apropriar-se dos contornos dessa escolha e refletir sobre ela, o que pode contribuir não somente para a evasão dos docentes como foi o caso de nove professoras da rede de 2010 a 2013 - mas também para a precarização do trabalho docente e, consequentemente, do processo de escolarização de estudantes público-alvo da Educação Especial.

Notou-se que, frente à constatação do baixo interesse dos professores pela atuação no $A E E$, a rede municipal de ensino estudada parece encontrar na indicação de professores com "perfil para trabalhar no AEE" por profissionais das 
Atos de Pesquisa em Educação - ISSN 1809-0354

Blumenau, v. 12, n.3, p.661-676, set./dez. 2017

DOI: http://dx.doi.org/10.7867/1809-0354.2017v12n3p661-676

equipes diretivas escolares uma solução paliativa. No entanto, considerando que a maioria dos docentes indicados é iniciante na rede e que essa indicação procede da direção escolar, compreende-se que se criam condições para dificultar a recusa deste professor a tal "convite", convertendo a indicação em uma prática de indução.

Considera-se que garantir que as vagas sejam preenchidas o mais rápido possível, sem que os determinantes desta baixa atratividade sejam analisados e tratados no contexto específico das redes, é uma maneira superficial de conduzir o processo de inserção dos professores no AEE e contribui para que os docentes permaneçam desinteressados em atuar neste serviço de ensino.

Neste sentido, sugere-se que sejam conduzidos estudos focalizados nesta problemática, a partir dos quais seja possível desenvolver medidas de intervenção que promovam mudanças significativas em termos de organização da escola, formação e condições de trabalho dos professores, fatores que quando fragilizados podem contribuir para este interesse reduzido dos docentes em atuar na referida modalidade de educação escolar.

\section{JULIANA TESTONI DOS SANTOS RENGEL}

Mestre em Educação pela Universidade da Região de Joinville - UNIVILLE.

\section{ALICIENE FUSCA MACHADO CORDEIRO}

Doutora em Educação: Psicologia da Educação pela PUC-SP. Professora Adjunta da Universidade da Região de Joinville.

\section{REFERÊNCIAS}

ALVES, N. N. L. Amor à profissão, dedicação e o resto se aprende: significados da docência em educação infantil na ambiguidade entre a vocação e a profissionalização. In: REUNIÃO NACIONAL DA ANPED, 29., 2006, Caxambu.

Anais. Caxambu, 2006, p. 01-17. Disponível em: <http://29reuniao.anped.org.br/trabalhos/trabalho/GT07-2570--Int.pdf>. Acesso em: 24 abr. 2015.

AULETE, C. Dicionário escolar da língua portuguesa. Rio de Janeiro: Lexikon, 2012.

BERNARDES, C. A. H. O trabalho docente no Atendimento Educacional Especializado pelas vozes de professoras especializadas. 2014. 179p. Dissertação (mestrado) - Universidade da Região de Joinville, Joinville. 


\section{Atos de Pesquisa em Educação - ISSN 1809-0354 \\ Blumenau, v. 12, n.3, p.661-676, set./dez. 2017 \\ DOI: http://dx.doi.org/10.7867/1809-0354.2017v12n3p661-676}

BRASIL. Resolução CNE/CEB $N^{\circ} 4$, de 2 de outubro de 2009. Institui diretrizes operacionais para o atendimento educacional especializado na educação básica, modalidade educação especial. Diário Oficial da União, Brasília, DF, 5 de outubro de 2009, Seção 1, p. 17.

CARNEVALE, L. B. et al. Atuação de professores de atendimento educacional especializado (AEE) em comunicação alternativa na região centro sul do Paraná. In: V CONGRESSO BRASILEIRO DE COMUNICAÇÃO ALTERNATIVA, 5., 2013, Gramado. Anais. Gramado, Universidade Federal do Rio Grande do Sul (UFRGS), 2013, p. 01-12. Disponível em:

<http://www.ufrgs.br/teias/isaac/VCBCAA/pdf/116016_1.pdf>. Acesso em: 28 jan. 2015.

DELEVATI, A. C. AEE: que atendimento é este? As configurações do atendimento educacional especializado na perspectiva da rede municipal de ensino de Gravataí/RS. 2012. 143p. Dissertação (mestrado) - Universidade Federal do Rio Grande do Sul, Porto Alegre.

FRANCO, M. L. P. B. Análise de conteúdo. 4. ed. Brasília: Liber Livro, 2012.

GATTI, B. A. Os professores e suas identidades: o desvelamento da heterogeneidade. Cadernos de Pesquisa, São Paulo, n. 98, p. 85-90, ago. 1996.

GATTI, B.; ANDRÉ, M. A relevância dos métodos de pesquisa qualitativa no Brasil. In: WELLER, W.; PFAFF, N. Metodologia da pesquisa qualitativa em educação: teoria e prática. 2. ed. Petrópolis, RJ: Vozes, 2011.

JANUZZI, G. Algumas concepções de educação do deficiente. Rev. Bras. Cienc. Esporte, Campinas, v. 25, n. 3, p. 9-25, maio 2004.

LIMA, C. C. S. Não ser, eis a questão: a constituição da identidade do professor inclusivo. 2010. 106p. Dissertação (mestrado) - Universidade de São Paulo, São Paulo.

MAZZOTA, M. J. S. Inclusão escolar e educação especial: das diretrizes à realidade das escolas. In: MENDES, E. G.; ALMEIDA, M. A. Das margens ao centro: perspectivas para as políticas e práticas educacionais no contexto da educação especial inclusiva. Araraquara, SP: Junqueira\&Marin, 2010.

MICHAELIS. Moderno dicionário da língua portuguesa (online). São Paulo: Melhoramentos, 2009. Disponível em: <http://michaelis.uol.com.br/moderno/portugues/index.php?lingua=portuguesportugues\&palavra=cair>. Acesso em: 18 nov. 2015.

MICHELS, M. H.; CARNEIRO, M. S. C.; GARCIA, R. M. C. O caráter conservador da perspectiva inclusiva na educação especial: as salas multimeios na rede municipal de Florianópolis. Revista Cocar, Belém, v. 6, n. 11, p. 17-28, jan./jul. 2012. 
Atos de Pesquisa em Educação - ISSN 1809-0354

Blumenau, v. 12, n.3, p.661-676, set./dez. 2017

DOI: http://dx.doi.org/10.7867/1809-0354.2017v12n3p661-676

MORAES, V. Livro de sonetos. São Paulo: Companhia das Letras, 2006.

RENGEL, J. T. S.; CORDEIRO, A. F. M.; STEINER, D. R. Identidade docente e inclusão escolar: um estudo sobre a produção acadêmica brasileira (2008-2014). In: XII CONGRESSO NACIONAL DE EDUCAÇÃO - EDUCERE, 12., 2015, Curitiba. Anais... Curitiba, Pontifícia Universidade Católica do Paraná (PUC-PR), 2015, p. 1358-1370.

SILVA, M. R. A formação dos professores de Atendimento Educacional Especializado de Goiás. 2014. 208p. Dissertação (mestrado) - Universidade Federal de Goiás, Goiás.

TARDIF, M. Saberes docentes e formação profissional. 15. ed. Petrópolis, RJ: Vozes, 2013.

TRAGTENBERG, M. Relações de poder na escola. Lua Nova, v. 1, n. 4, mar. p. 68$72,1985$. 